Special issue of the 3rd International Conference on Computational and Experimental Science and Engineering (ICCESEN 2016)

\title{
Optical Properties of Soda-Lime-Silica Glasses Doped with Eggshell Powder
}

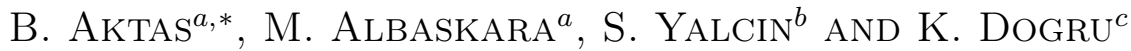 \\ ${ }^{a}$ Harran University, Mechanical Engineering Department, Sanliurfa, Turkey \\ ${ }^{b}$ Harran University, Physics Department, Sanliurfa, Turkey \\ ${ }^{c}$ Harran University, Institute of Natural and Applied Sciences, Sanliurfa, Turkey
}

\begin{abstract}
The optical properties of soda-lime-silica glasses doped with eggshell powder were investigated using UVvisible and the Fourier transform infrared spectroscopies. Pure soda-lime-silica glass, which is colorless and transparent, turned dark green after the addition of the eggshell powder. When the eggshell powder content was $\geq 3 \mathrm{wt} \%$, the glass became translucent. The maximum wavelengths in the UV spectra of the soda-lime-silica glasses doped with $0.5,1,3$, and $5 \mathrm{wt} \%$ eggshell powder were observed at 300.20, 277.40, 284.40, and $312.40 \mathrm{~nm}$, respectively. The Fourier transform infrared spectra of the eggshell-doped soda-lime-silica glass samples were very similar to that of the base undoped glass. The bands at approximately $770-820 \mathrm{~cm}^{-1}$ could be attributed to the $\mathrm{Si}-\mathrm{O}-\mathrm{Si}$ symmetric stretching of the bridging oxygen between the tetrahedra, while the bands at approximately $970 \mathrm{~cm}^{-1}$ were related to the $\mathrm{Si}-\mathrm{O}-\mathrm{Si}$ antisymmetric stretching of the bridging oxygen within the tetrahedra.
\end{abstract}

DOI: 10.12693/APhysPolA.132.442

PACS/topics: soda-lime-silica glass, eggshell powder, optical properties, FTIR spectra

\section{Introduction}

The optical properties of glass play an important role in determining its suitability for various everyday applications, including as a material for glass containers and windows. The optical quality of the glass used for camera lenses, telescope mirrors and lenses, microscope lenses, and fiber optic products is of even greater importance. Sunlight is a combination of radiation of three different wavelengths, namely, ultraviolet (UV), visible, and infrared (IR) radiation. The wavelength of UV light is lower than $380 \mathrm{~nm}$, while that of IR light is higher than $780 \mathrm{~nm}$. Light with wavelengths of $380-780 \mathrm{~nm}$ is called visible light. Visible light consists of purple, blue, green, yellow, orange, and red colors, depending on the wavelength [1-7].

Soda-lime-silica (SLS) glasses have been found to be suitable optical materials for a number of applications, since they show a high transparency, low melting point, high thermal stability, and good rare-earth-ion solubility. Further, SLS glasses exhibit superior chemical resistance and are optically transparent at the excitation and lasing wavelengths [8]. In addition, they are more compatible with the processes employed for fabricating optical devices than are other glasses [9]. Hence, the objective of this study was the preparation of soda-limesilica glasses that feature different amounts of eggshell (ES) waste products, and it was to investigate the the optical properties of SLS glasses doped with ES powder using UV-vis and the Fourier transform infrared spectroscopy techniques.

*corresponding author; e-mail: baktas@harran.edu.tr

\section{Materials and procedure}

In this study, a SLS powder was used as the matrix material, while ES powder was used as the additive. The SLS and ES powders were prepared by grinding SLS glass (Trakya Glass Industry Co.) and ES waste, respectively. The chemical compositions of the powders used in the study were determined using inductively coupled plasma mass spectrometry (ICP-MS) and are given in Table I.

TABLE II

Chemical analysis results [wt\%] of the powders used in this study.

\begin{tabular}{c|c|c|c|c|c|c|c|c|c}
\hline \hline & $\mathrm{SiO}_{2}$ & $\mathrm{Al}_{2} \mathrm{O}_{3}$ & $\mathrm{CaO}$ & $\mathrm{K}_{2} \mathrm{O}$ & $\mathrm{Fe}_{2} \mathrm{O}_{3}$ & $\mathrm{MgO}$ & $\mathrm{MnO}_{2}$ & $\mathrm{Na}_{2} \mathrm{O}$ & $\mathrm{TiO}_{2}$ \\
\hline $\mathrm{SLS}$ & 71.5 & 1.5 & 9.5 & - & 0.024 & 2 & - & 15.5 & 0.08 \\
$\mathrm{ES}$ & 0.03 & 0.0163 & 98.43 & 0.2186 & 0.0036 & 0.936 & 0.00435 & 0.363 & -
\end{tabular}

Different amounts of the ES powder (0.5, 1, 3, and $5 \mathrm{wt} \%$ ) were mechanically mixed with the SLS powder. The mechanical mixing was performed in an attritor-type mixer at $200 \mathrm{rpm}$ for $1 \mathrm{~h}$. The powders were then pressed at $250 \mathrm{MPa}$ in a single-axis die with a radius of $32 \mathrm{~mm}$; this yielded pellets with a diameter of $32 \mathrm{~mm}$ and thickness of $6 \mathrm{~mm}$. The glass samples were prepared by melting the undoped and ES-doped SLS powders in a graphite mold at $1300^{\circ} \mathrm{C}$ for $2 \mathrm{~h}$ to ensure homogeneity. The molten glass was then quenched in the mold. After the quenching process, the samples were formed in a squareshaped graphite mold at $1100^{\circ} \mathrm{C}$. The formed samples were annealed at $500^{\circ} \mathrm{C}$ for $3 \mathrm{~h}$ and then slowly cooled to room temperature inside the furnace. For microstructural investigations, the surfaces of the samples were successively ground using 120, 240, 400, 600, 800, and 1200 grit $\mathrm{SiC}$ papers and subsequently polished using 6,3 , and $1 \mu \mathrm{m}$ diamond suspensions. The surfaces of the polished samples were etched with HF acid for 1 min and then analyzed using an optical microscope. The densities of the 
samples were measured by the Archimedes principle using distilled water. The electronic absorption spectra of the samples were obtained using a Perkin Elmer Lambda $25 \mathrm{UV}$-visible spectrophotometer for wavelengths of 200 $400 \mathrm{~nm}$ at room temperature. The Fourier transform infrared (FTIR) spectroscopy was peformed on the glass samples using a Perkin Elmer spectrometer with an instrument resolution of $1 \mathrm{~cm}^{-1}$ for wave numbers of 500 $4000 \mathrm{~cm}^{-1}$.

\section{Results and discussion}

Figure 1 shows the microstructures of the undoped and ES-powder-doped SLS glasses. After 1 min of chemical etching (HF acid), a number of superficial cracks that extended along the depth direction were observed. On the other hand, no cracks were visible before the chemical treatment. Thus, it can be surmised that the visible cracks were formed because of the effect of the acid attack on previously present randomly oriented microcracks. The dissolution of the crests near these surface grooves led to the hollow clusters turning into larger, nearly homogeneous craters.

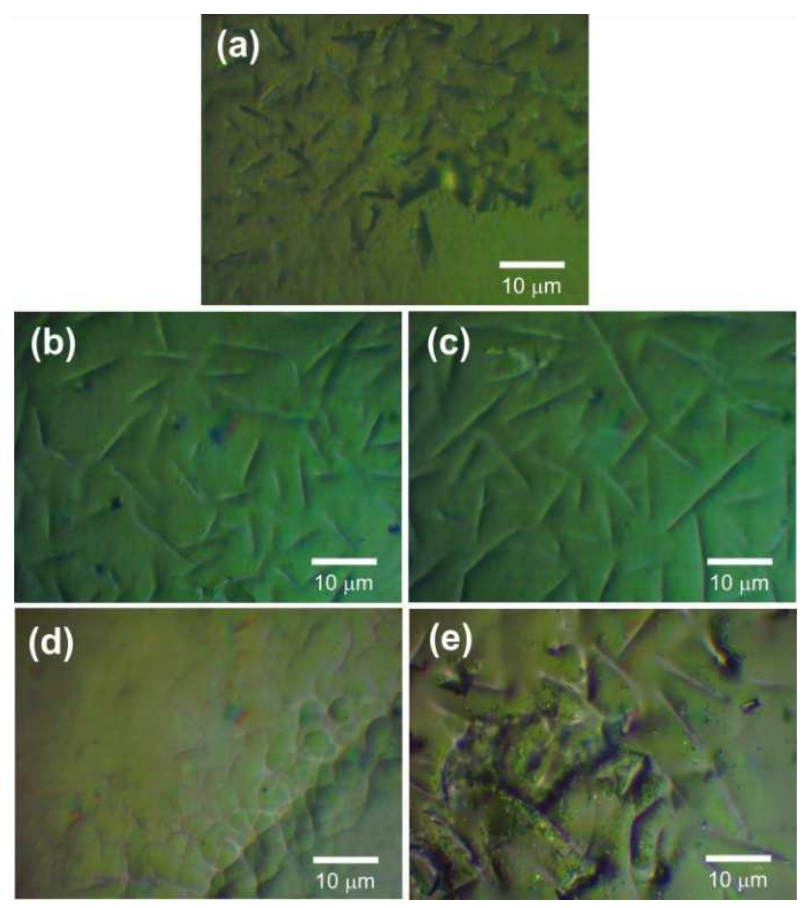

Fig. 1. Optical micrographs of the SLS glasses doped with (a) 0 , (b) 0.5 , (c) 1 , (d) 3 , and (e) 5 wt\% ES powder.

Photographs of the annealed pure SLS and ES-powderdoped glasses are shown in Fig. 2. The pure SLS glass was colorless and transparent, but turned dark green after the addition of the ES powder. Further, when the ES powder content was $\geq 3 \mathrm{wt} \%$, the glass became translucent, owing to the presence of $\mathrm{Fe}_{2} \mathrm{O}_{3}$ within the ES powder.

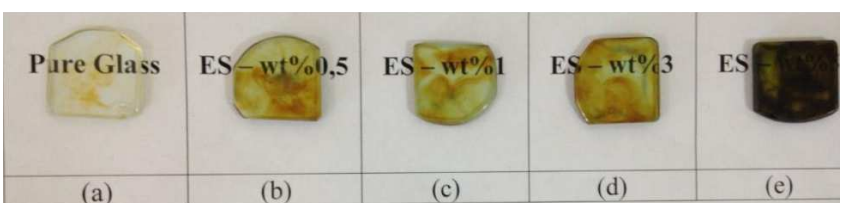

Fig. 2. Photographs of the SLS glasses doped with (a) 0 , (b) 0.5 , (c) 1 , (d) 3 , and (e) 5 wt $\%$ ES powder.

The UV-visible absorption spectra of the SLS glass samples containing $0.5,1,3$, and $5 \mathrm{wt} \%$ ES are shown in Fig. 3. The SLS glass sample containing $0.5 \mathrm{wt} \%$ ES powder showed strong UV absorption, exhibiting a peak at $270 \mathrm{~nm}$ and a small band at $300 \mathrm{~nm}$. Similarly, the SLS glass sample containing $1 \mathrm{wt} \%$ ES powder also showed broad and strong UV absorption, with its spectrum containing a peak at $277 \mathrm{~nm}$ and a small band at approximately $235 \mathrm{~nm}$. The spectrum of the third glass sample, which had 3 wt\% ES powder added, contained two strong UV bands, at approximately 270 and $284 \mathrm{~nm}$, respectively. Finally, in the case of the sample with $5 \mathrm{wt} \%$ ES powder as well, broad and strong UV absorption was observed, with its spectrum containing peaks at 291 and $312 \mathrm{~nm}$ as well as a small band at approximately $242 \mathrm{~nm}$.

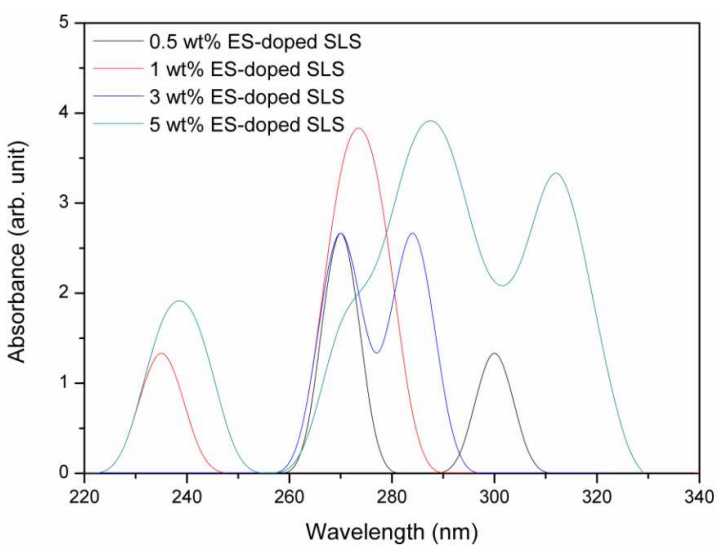

Fig. 3. Absorption spectra of the ES-powder-doped SLS glass samples.

Previous studies on the optical absorption properties of silicate, borate, and phosphate glasses have suggested that the presence of transition metal ions even in small amounts (in particular, that of ferric iron ions at trace (ppm) levels) has a negative effect on the UV transmission properties of the glasses $[10,11]$. İbrahim et al. reported observing strong UV absorption bands in the case of SLS glass containing cement dust and transition metal oxides, which were attributable to the absorption of trace iron impurities present as contaminants within the raw materials used as well as in the cement dust [11].

Figure 4 shows the FTIR spectra of the ES-powderdoped SLS glasses. The spectra of the samples were similar to that of the base undoped glass, with the differences between the various spectra being very small. 
The peak observed at $1455.64 \mathrm{~cm}^{-1}$ was related to carbonate groups, while the bands seen at 2916.48 and $2847.47 \mathrm{~cm}^{-1}$ were attributable to the symmetric and symmetric stretching modes of the interstitial $\mathrm{H}_{2} \mathrm{O}$ molecules. Further, the bands at approximately 770 $820 \mathrm{~cm}^{-1}$ were attributable to the $\mathrm{Si}-\mathrm{O}-\mathrm{Si}$ symmetric stretching of the bridging oxygen between the tetrahedra. Finally, the bands at approximately $970 \mathrm{~cm}^{-1}$ were related to the $\mathrm{Si}-\mathrm{O}-\mathrm{Si}$ antisymmetric stretching of the bridging oxygen within the tetrahedra.

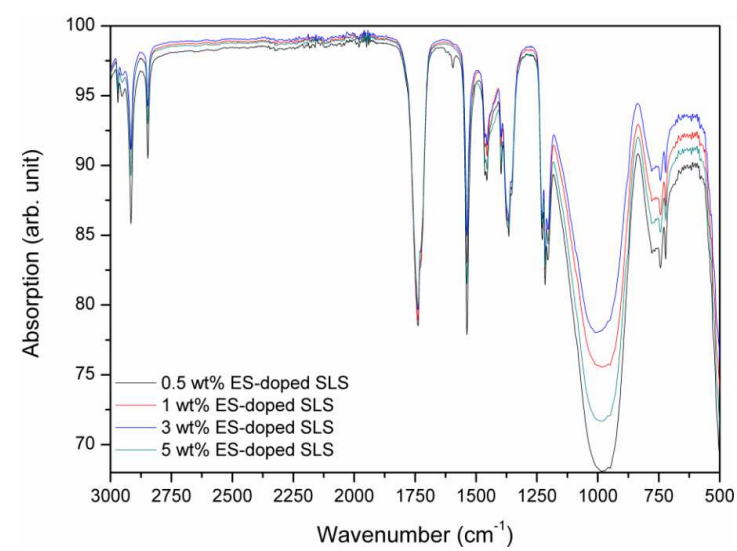

Fig. 4. FTIR spectra of the ES-powder-doped SLS glass samples.

Lee et al. have suggested that the change in the position of the peak at $1050 \mathrm{~cm}^{-1}$ in the IR reflection band is related to a change in the glass structure, as indicated by the change in the fictive temperature. They also reported that the bands shift to higher frequencies when the glass is treated at higher temperatures and to lower frequencies when it is treated at lower temperatures [12].

\section{Conclusions}

In this study, ES-powder-doped SLS glasses were produced by the melt-quench technique. It was observed that the glass samples turned green when the ES powder was doped into the glass matrix. The pure SLS glass was colorless and transparent, whereas the ES-powder doped samples were dark green. Further, increasing the ES powder content increased the color intensity at the centers of the samples, with the absorption also increasing with the ES powder content. The FTIR spectra of the SLS glasses doped with the ES powder in amounts of $0.5-5 \mathrm{wt} \%$ contained a band at approximately $1455.64 \mathrm{~cm}^{-1}$, which corresponded to the stretching of the carbonate groups, as well as bands at 2916.48 and $2847.47 \mathrm{~cm}^{-1}$, which could be attributed to the asymmetric and symmetric stretching modes of the interstitial $\mathrm{H}_{2} \mathrm{O}$ molecules.

\section{Acknowledgments}

This work was supported by HUBAK (the Scientific Research Projects Commission of Harran University, Sanliurfa, Turkey) under project number 14170. The authors thank the commission for the financial support.

\section{References}

[1] R.H. Doremus, Glass Science, Wiley, New York 1973, p. 319.

[2] H. Rawson, Properties and Applications of Glasses, Elsevier, Amsterdam 1980, p. 156.

[3] B. Aktas, M. Albaskara, S. Yalcin, K. Dogru, Archiv. Mater. Sci. Eng. 82, 57 (2016).

[4] B. Kiris, O. Bingol, R. Senol, A. Altintas, Acta Phys. Pol. A 130, 55 (2016).

[5] M. Ustundag, B.G. Yalcin, M. Aslan, S. Bagci, Acta Phys. Pol. A 130, 98 (2016).

[6] I.A. Kariper, O. Baglayan, F. Gode, Acta Phys. Pol. A 128, B-219 (2015).

[7] A.A. Barzinjy, M.M. Zankana, Acta Phys. Pol. A 130, 239 (2016).

[8] H. Lin, E.Y.B. Pun, X.R. Liu, J. Non-Cryst. Solids 283, 27 (2001)

[9] S.A. Boussaa, A. Kheloufi, N.B. Zaourar, F. Kerkar, Acta Phys. Pol. A 130, 133 (2016).

[10] M.A. Ouis, H.A. El Batal, M.A. Azooz, A.M. Abdelghany, Indian J. Pure Appl. Phys. 51, 11 (2013).

[11] M.M. Ibrahim, M.A. Fanny, M.Y. Hassaan, H.A. ElBatal, Silicon 8, 443 (2016).

[12] Y.K. Lee, Y.L. Peng, M. Tomozawa, J. Non-Cryst. Solids 222, 125 (1997). 